\title{
Educating critically about language and intercultural communication: What and who is at stake?
}

\author{
Chantal Crozet, Kerry Mullan, Jing Qi, and Masoud Kianpour
}

\begin{abstract}
This paper reflects on the literature on Critical Language and Intercultural Communication Education in light of learnings gained from designing and delivering a course titled 'Intercultural Communication' over four years to large cohorts of firstyear tertiary students in Australia. It is based on a qualitative research project which involves the analysis of two sets of data: a) ethnographic notes from teaching staff meetings, tutors' interviews, and tutorial observation, and b) student formal and informal feedback surveys as well as focus group discussions. The paper explores what and who is at stake when teaching and learning about language and intercultural communication from a critical perspective. It unveils from a praxis perspective (theory informed by practice and vice versa) the deeply political and ethical level of engagement that is required of teachers, the kind of metalinguistic and metacultural knowledge, as well as the kind of disposition towards critical thinking and reflexivity, that are called for when teaching and learning in this domain in an Australian tertiary environment.
\end{abstract}

Keywords: criticality; education; intercultural communication; interculturality; language; reflexivity

Received 14 December 2020; revised version received 22 June 2021; accepted 18 October 2021. Corresponding author: Chantal Crozet, RMIT University, Australia (chantal.crozet@rmit.edu.au).

\section{Introduction}

This article is a contribution to the emerging research on Intercultural Communication courses (cf. Eisenchlas \& Trevaskes, 2003; Hatoss, 2019; Yi-jung Hsieh, 2019) which have now become a mandatory component of many degree programs around the world, including in Australian universities (Diaz \& Moore, 2019). It aims to provide insights into the practice of teaching a course on Intercultural Communication in Australia with a focus on language, exploring to what extent its orientation in terms of content and pedagogical approach aligns with 
the key tenets of the literature on Critical Language and Intercultural Communication Education. It is based on a qualitative research project on an existing Intercultural Communication course taught in an Australian tertiary environment, coordinated by the first author (Crozet) and co-taught with a team of casually employed tutors. This project originally sought to understand the reasons behind the highly polarised student feedback on the course.

Sections one and two explore the course coordinator's positionality and elaborate on what we mean by 'Critical Language and Intercultural Communication Education'. It does so as a way of providing a rationale for the choice of content and pedagogical approach for the course under scrutiny. The two first sections also identify the nature of the other three authors' contributions to the article. Section three provides background information on the course and presents the study. Section four discusses learnings from teaching the course for the first author, informed by the study's findings and the input of the other three authors, highlighting the kind of challenges that are at stake when teaching and learning about language and intercultural communication from a critical perspective. It unveils the deeply political and ethical level of engagement that is required of a course coordinator and teaching staff, the disposition towards critical thinking and reflexivity required of both teachers and learners, as well as the kind of metalinguistic and metacultural knowledge that are called for from a praxis perspective in this domain. Section five offers concluding remarks and prospects for further research.

\section{First author's positionality and nature of the other three authors' contributions}

In Australia, academics in charge of Intercultural Communication courses in a university context base their curricula largely on their own and varying disciplinary expertise, typically: psychology, communication, linguistics, anthropology, and in more recent times, applied linguistics. As noted in the literature, as more applied linguists are now appointed to teach in both foreign languages and Intercultural Communication, increasingly stronger connections are made between the two areas (Diaz \& Moore, 2019; Martin, Nakayama, \& Carbaugh, 2014; Roby, 1992).

As noted earlier, the first author (Crozet) is the current coordinator and lecturer of the course. She has a background in French and Spanish literary studies, applied linguistics, and the teaching of foreign languages. Crozet's research has contributed to the development of language and culture pedagogy in Australia from a critical intercultural perspective since its emergence in the mid-1990s (Crozet 1996; 2016; 2018; Crozet \& Diaz, 2020; Diaz, 2013; Dasli \& Diaz, 2017; Kohler, 
2015; Liddicoat \& Crozet, 2001; Liddicoat \& Scarino, 2013; Lo Bianco, Liddicoat, \& Crozet, 1999; Lo Bianco \& Crozet, 2003; Mullan, 2015, 2017). This body of literature evolved from concerns regarding the lack of teaching culture in verbal interactions, prompted at the time by growing interest in cross-cultural pragmatics and Conversation Analysis. It evolved over time to include the teaching of all other aspects of cultural content closer to contextual knowledge embedded for instance in history, literature, food, gender, or film studies (Crozet \& Diaz, 2020). Crozet's teaching background and research interests explain the focus on culture embedded in verbal and non-verbal human interaction for half of the course in question.

The second author (Mullan) has a background in applied linguistics, crosscultural pragmatics, differing interactional styles, and the teaching of French as a foreign language from a critical intercultural perspective (see references above). She participated in all stages of production of the research project, from its initial framing, through to the data collection for the study and the co-writing of the article with the first author.

The third author (Qi) and fourth author (Kianpour) participated in the initial framing of the study including its rationale, research methodology, data selection and data analytical framework. Their insights were particularly valuable in these initial stages: Qi has a background in international and transnational education, sociology of education and education equality, language education and teacher education; and Kianpour researches social psychology, sociology of emotions and intercultural communication. Kianpour was also a tutor in the course in 2019 and assisted with the focus group data collection. Both also provided feedback on the article's drafts.

\section{On Critical Language and Intercultural Communication Education}

We refer to 'Critical Language and Intercultural Communication Education' by way of signalling that the theoretical backbone of the article sits within the body of literature with a particular focus on what Dasli and Diaz (2017) coined 'the critical turn' within language and intercultural communication pedagogy at large.

We are well aware that scholars with a common interest in interculturality in human interaction for educative purposes come from various sub-areas of education and research. These sub-areas are not limited to the teaching of 'foreign languages' and of 'intercultural communication'; they also include 'intercultural education'. 'Global stars' in interculturality, as referred to by Simpson and Dervin (2019), are associated with these different sub-fields of education. Michael Byram and Claire Kramsch's research, for instance, is anchored in foreign languages education, whereas Milton J. Bennett and Geert Hofstede's work is associated with 
Intercultural Communication education/training. By contrast, Fred Dervin and colleagues' research is anchored in intercultural (compulsory and higher) education. These distinctions help explain the different nuances and emphasis found in the literature, not only on the meaning of 'interculturality' and of 'criticality', but also in terms of the importance given to language/linguistics in the definition and use of these concepts. Ultimately, regardless of the sub-field they associate with, researchers and practitioners in the field of language and intercultural communication education are informed by their selection of literature. They not only decide what interculturality and criticality mean to them (Dervin, 2016), they also decide how they want to engage with it in education.

The critical pedagogical approach of the Intercultural Communication course under study is based on our understanding of 'criticality', broadly defined by Dasli and Diaz (2017, p. 11) as aiming for '... the development of individuals' cognitive skills and attitudes (e.g., critical thinking, self-reflexivity) and as an overarching pedagogical framework where the term acquires additional ethical, social and political connotations'.

One definition of 'interculturality' which resonates closely with Crozet's approach to teaching Intercultural Communication is echoed in Abdallah-Pretceille (2006, p. 480):

No fact is intercultural at the outset, nor is the quality of 'intercultural' an attribute of an object, it is only intercultural analysis that can give it this character. It is the look of the beholder that creates the object and not the other way round.

At the core of Abdallah-Pretceille's insight is the notion of interculturality as primarily 'analysis' - that is the ability to question, reflect on, and interpret an object, and by extension, human interactions in their varying pluralistic contexts. These are the key aims of the course, which prompted the research project that inspired this article. We use the word 'pluralistic' as inclusive of language, culture, class, language, religions, gender, and any other factors which can affect the interpretation of meaning in any given situation. Above all, interculturality to us signals 'a process, something in the making' (Dervin, 2016, p. 1). A course on intercultural communication is an ideal place to make this processing as critical for students as possible. Whether it ultimately contributes to their political and ethical engagement for greater social justice remains to be seen.

In support of her concept of interculturality, Abdallah-Pretceille (2006, p. 468) suggests the use of 'culturality' rather than 'culture' to refer to 'cultural processes in the light of their generation of behaviours and discourse'. Culturality in this sense is a way of recognizing that individuals have the agency of being and 
acting according to their chosen codes of reference. However, defining 'interculturality' necessarily refers specifically to interaction between different groups of people which have 'an essential kind of difference', without which there would be no relevance to speak of 'inter-culturality' (Mikander, Zilliacus, \& Holm, 2018). This does not exclude the recognition that people are not totally bound by culture, nor that they experience and use cultures as liquid rather than static entities (Bauman, 2004; Verschueren, 2008). For these reasons, the course under scrutiny does not shy away from using the concept 'culture', albeit from an interpretive perspective which favours inter-subjective understanding.

The course objectives and content aim to support the development of interculturality as broadly defined in the official description of the course objectives:

to equip students with the knowledge, skills and critical thinking to enable them to communicate, negotiate and continue to learn across diverse social and cultural settings, as well as to prepare them for work, study or research in intercultural environments. It aims to provide students the opportunity to develop an enhanced awareness of their own social and cultural background/context and how that can impact on intercultural communication and processes. ${ }^{1}$

Knowledge, skills, critical thinking, and self-awareness are key to these objectives and will be discussed further in light of the study's findings.

There are no uniform approaches to Intercultural Communication university courses in Australia. Commonly, Intercultural Communication course coordinators use a textbook as de facto curriculum. However, after evaluating a number of textbooks and finding none with sufficient focus on both language and culture in an Australian context, and none suitable for students without a language or linguistics background, the coordinator chose not to use a textbook in order to better align the course content with the objectives she had set. This meant compiling a list of essential and supplementary readings from multiple sources (a total of 60 readings), updated each year.

As mentioned earlier, the first part of the course focuses on culture in language largely based on discourse analysis theory (i.e., cross-cultural and intercultural pragmatics, as well as conversation analysis). Metalinguistic

\footnotetext{
${ }^{1}$ In addition, the university offers several microcredentials in the area of cross-cultural awareness (primarily from the realm of business): 1/Building Cultural Intelligence; 2/Cultural adaptation; 3/Cross-cultural communication; 4/Cultural differences and similarities; 5/Global Cultural Awareness (Internship); 6/Diversity matters. We are encouraged to promote those which we see as the most relevant for this course (numbers 3, 4, and 6) on the learning portal. We ask students who choose to undertake any of these microcredentials to approach them with a critical eye.
} 
knowledge is used in this case as critical tools to unveil the dynamic relationship between language(s) and culture(s), in order to better deconstruct it, rather than to reinforce essentialist views of either (see Dervin \& Liddicoat, 2016, for further illustrations of this perspective). In doing so, a good deal of time is spent on distinguishing between essentialist and constructionist approaches towards culture, helping students understand how everyday language is used, often uncritically, to perpetuate generalised characteristics of a particular culture and that how knowledge of intercultural communication can challenge this process.

The second part of the course focuses more specifically on key factors in meaning-making processes. It addresses interculturality in the context of discussions on avowed versus ascribed identities, as well as individual agency, from an intersectional perspective. It considers the relevance of gender, race, and social class (based respectively on discourse and gender theory [see Kendall \& Tannen, 2001], raciolinguistics [Alim, Rickford, \& Ball, 2016], and sociolinguistics) within the power dynamics of intercultural human interaction. The challenge is to keep a focus on how such variables (gender, race, class, and identity/individual agency) affect intercultural communication, that is in situations where an essential linguistic and culturally-based difference is present. As students are now more and more accustomed to exploring intersectionality in their respective undergraduate degrees, they often bring to the course some prior background knowledge in this area. However, doing language and culture work from an intersectional perspective as reflected in real intercultural human communicative acts, as the course aims to do, is not easily achieved.

Throughout the course, both Indigenous-Australian and Anglo-Australian are used as the two main sets of cultures of reference from which other cultural systems are explored from a critical intercultural perspective. One week is dedicated to Indigenous and Anglo-Australian communicative styles, largely based on research conducted in this area in legal contexts (Eades, 2004, 2008; Bowen, 2019; Gibbons, 2003), and another week to aspects of Indigenous-Australian cultural systems as relevant to intercultural communication more broadly in Australia (Alia, 2014; Hattersley, 2014; Heiss, 2018; Moore, 2016). ${ }^{2}$

The first author does not claim to be an expert in all areas that are touched on in the course, but her educational vision for it encompasses them all. Where possible, guest lecturers are invited to speak, especially for the second part of the course.

Having situated the first author's stance within Critical Language and Intercultural Communication Education and towards the course, as well as the

\footnotetext{
${ }^{2}$ The references mentioned in this paragraph correspond to the readings listed in the course for those weeks.
} 
contributions of the other three authors, the next section provides further background information on the course.

\section{Background information on the Intercultural Communication course}

This section provides further general information on the course, including information on student profiles and the teaching team in 2019 when the study was undertaken.

\section{Overview}

Intercultural Communication is a twelve-week first year core course for six undergraduate programs in the School of Global, Urban and Social Studies at RMIT University in Australia, reflecting the now worldwide recognition of the importance of intercultural communicative competence in graduate attributes (Hua, Handford, $\&$ Young, 2017). The course was delivered face-to-face in 2018 and 2019 when the data were collected, but in 2020 and 2021 due to Covid-19, the course was delivered online with asynchronous lectures and synchronous tutorials.

\section{Student cohort}

While the majority of students are full-time first-year students aged 19, the course also attracts some older and some part-time students. In 2019, there were approximately 3.5 times more students identifying as female than male (411 vs. 116) Almost all the students are domestic, but the course also attracts some international and exchange students. Domestic students also represent a range of circumstances and characteristics: many are from an apparently Anglo-Australian background and many are first- or second-generation migrants from an array of culturally and linguistically diverse communities; a very small minority have an Indigenous-Australian background and other students may be fairly recently arrived migrants or refugees from various countries. The rich multilingual and pluricultural diversity of student backgrounds is not visible from student enrolment records. The various undergraduate degrees also demand different $\mathrm{ATAR}^{3}$ scores for admission into their program, so, although there has been much debate in the Australian press in recent times about the relevance and reliability of this score as a predictor of student success at university, to some extent it remains another variable in the student cohort.

Out of the 527 enrolled students in 2019, most were enrolled in the Bachelor of Criminology and Psychology (149). This was followed by the Bachelor of Legal

\footnotetext{
${ }^{3}$ The Australian Tertiary Admission Rank is the primary criterion for domestic student entry into undergraduate courses in Australian public universities.
} 
and Dispute Studies (96), the Bachelor of Social Work (Honours) (95), the Bachelor of International Studies (90), and the Bachelor of Social Science (Psychology) (52). Students from other programs across the university make up 38 of the enrolments, with 8 enrolments from the Diploma of Languages (currently being discontinued). Students' diverse academic interests account in part for the different expectations they have of the course.

What this complex diversity of student profiles means in practice is that course content, assessments, the lecturer, and tutors all have to take into account a range of disciplinary interests and expertise, maturity, existing knowledge and/or life experience, English (and other) language proficiency, cultural backgrounds, and so on, to a greater extent than many other courses.

\section{Teaching team}

The 2019 Intercultural Communication Course (ICC) teaching team included eleven tutors. The coordinator selects the tutors based firstly on academic qualification (minimum Master's level) combined with their main research interest, which includes language and/or culture as a guiding principle.

Teachers have long been acknowledged as key players in the success of any educational undertaking, and research on intercultural communication courses has demonstrated teachers' key role in modelling intercultural communicative capabilities in and beyond the classroom (Gudykunst, Ting-Toomey, \& Wiseman, 1991; Lee et al., 2012). Taking this into account, the tutors, where possible, must have had substantial direct experience with people from diverse cultures, in either their personal or professional life, ideally both.

Weekly meetings are held for the whole team where tutors share their and students' experiences from the preceding week's tutorial, followed by an overview and discussion of the lecture and tutorial activities for the following week.

The above background information highlights the challenges of delivering the course: catering for extensive student academic, cultural, and linguistic diversity; supporting and nurturing an equally diverse group of tutors; and teaching without a textbook.

\section{The study}

The rationale for the study originated from the end of semester Course Evaluation Surveys (CES) in 2016 and 2017 which showed quite polarised views of student satisfaction with the course under the current coordinator. In order to address these concerns, and for quality assurance purposes, a pilot study was undertaken on the course in 2018. It was led by the two first authors: the coordinator/lecturer of the 
course (Crozet) and a colleague who did not teach into the course (Mullan). The primary aim was to try to better understand the diverse student responses to the course. Preliminary data were collected in the form of the usual annual informal and formal (anonymous and optional) student feedback surveys, as well as tutorial observation and tutor interviews undertaken for the purposes of this project. The collection of student feedback and tutorial observation were as described below for 2019. In addition, in 2018, the tutors were asked the following questions:

1. What did you think of the course overall?

2. What were the most challenging aspects for you as a tutor?

3. Do you have any comments about the assessment scheme?

4. Do you think that the reading logs improved students' quality of engagement in class discussion?

5. Do you think that the course content is appropriate for a 1st year course?

6. What can you say about your experiences of students' responses/ attitudes towards tutorials' activities?

7. Would you change anything in the course?

8. Would you get rid of some content?

9. Would you add any new content?

10. Do you think that the course should have a follow-up course (such as 'Intercultural mediation and dialogue')?

The data were analysed to identify the main themes, strengths, and challenges of the course, leading to the formulation of the following research question for the larger 2019 project and the focus of this paper: What and who-in other words which aspects of society, identity, and self are at stake when teaching and learning about language and interculturality from a critical perspective? Answers to this question were viewed as the first step to initiate changes to the course addressing particularly the complaints of the most dissatisfied students. The following sections describe the collection, analysis, and findings of the data.

\section{Data collection}

We collected primarily qualitative data for this study, as detailed in Table 1. Data from the 2018 pilot study are included for information since they informed the direction of the 2019 project but are not included in the analysis and discussion of the findings, unless stated. The 2019 data were obtained from several sources, to strengthen the findings from the pilot study and to enable us to delve more deeply into the data: notes from tutorial observations and weekly teaching staff meetings; 
qualitative comments in the mid-semester informal student feedback; qualitative comments in the university prescribed formal CES; and student focus groups. The range of data and participants go some way towards counteracting the necessary caveats around the subjectivity and representativity of (optional) student feedback. The small quantitative dataset comes from the responses to the Likert Scale questions in the CES. While the student formal and informal feedback surveys are administered annually in this course, the other sets of data were collected specifically for this study.

\begin{tabular}{|l|l|}
\hline $\mathbf{2 0 1 8}$ pilot study (678 students) & \\
Notes from tutorial observations & 14 tutorials observed \\
Notes from teaching staff meetings & $\begin{array}{l}13 \text { meetings } \\
14 \text { tutors }\end{array}$ \\
$\begin{array}{l}\text { Tutor interviews } \\
\text { Mid-semester informal feedback }\end{array}$ & $\begin{array}{l}51 \text { responses } \\
\text { CES }\end{array}$ \\
\hline $\mathbf{2 0 1 9}$ study (528 students) & \\
& \\
Notes from tutorial observations & 11 tutorials observed \\
Notes from teaching staff meetings & 13 meetings \\
Mid-semester informal feedback & 22 responses \\
CES & 147 responses \\
Student focus groups & $4 \times 60$-minute focus groups with 17 students \\
\hline
\end{tabular}

Table 1. Data sets

The 2019 data collection is explained below.

\section{Notes from tutorial observations}

The course coordinator observed one tutorial each week. The aim was to observe every tutor at least once, noting how they engaged with students, how the tutorial material was dealt with in class, and to observe the students' engagement with the activities and discussions, as well as to record any noteworthy student comments.

\section{Notes from teaching staff meetings}

The course coordinator took notes at thirteen weekly meetings with herself and fourteen tutors. (The first meeting was essentially a training session before the start of semester.) The aim here was to collect important observations from the tutors about the course, and any challenges they and students had encountered. 


\section{Mid-semester informal feedback}

In week 6, students were asked for their feedback on the course content, assessment, lectures, and tutorials using the GoSoapBox Student Response System. This is not a university prescribed collection of feedback, and the quality (and quantity) of responses vary, but overall, this has been found to be a useful way to improve the course immediately where possible, with the added benefit of potentially improving the end of semester CES scores. The questions were as follows:

1. What do you think of the course content/readings/videos?

2. What do you think of the assessment tasks?

3. What do you think of the lectures?

4. What do you think of the tutorials?

\section{Course Evaluation Surveys}

From weeks 9-12, students are asked to complete the CES. Seven standard Likert Scale questions are asked to ascertain their overall percentage of satisfaction with the course and the teaching staff:

1. The teaching staff are extremely good at explaining things.

2. The teaching staff normally give me helpful feedback on how I am going in this course.

3. The teaching staff in this course motivate me to do my best work.

4. The teaching staff work hard to make this course interesting.

5. The staff make a real effort to understand difficulties I might be having with my work.

6. The staff put a lot of time into commenting on my work.

7. Overall, I am satisfied with the quality of this course.

In 2019, the coordinator selected seven further Likert Scale questions from an extensive bank of additional questions:

8. I consider what I learned valuable for my future.

9. I learned to explore ideas confidently with other people.

10. I was able to put the time required into completing the work required for this course.

11. In this course students were encouraged to form and express their own ideas and opinions.

12. I worked hard in this class.

13. The material provided on Canvas helped me with my studies.

14. I listened to the online lectures. 
In addition, students are asked the following standard two open-ended questions: What are the best aspects of this course? What aspects of this course are in most need of improvement?

Results are indicative of students' views as a fifth of students (125 out of 527) completed the survey.

\section{Student focus groups}

Four 60 -minute focus groups were conducted in week 12 by three different tutors, who were briefed by the coordinator on how to run them. Seventeen volunteer students were interviewed (in groups of three to five) about their expectations and experience of the course, and the learning they felt they had achieved, as follows:

1. What did you expect to learn at the beginning of this course?

2. How would you describe your learning experience in this course in relation to your expectations?

3. Has this course been useful to you? If yes, in what ways?

4. Which topics in this course did you enjoy or dislike? Why? Could you give some examples?

5. Has the course confirmed or challenged perceptions of yourself and others in any way? Could you share some examples?

6. Do you think this course will help you in the future to communicate interculturally more constructively than you had been able to before? Why or why not?

The focus groups were recorded and transcribed.

\section{Data analysis}

An inductive content/thematic approach was used to analyse the data in this study. Content or thematic analysis is used frequently in the social sciences to make replicable and valid inferences by systematically examining patterns and interpreting and coding textual material to determine recurring themes. Braun and Clarke (2006, p. 79) define thematic analysis as 'a method for identifying, analysing and reporting patterns within data'. This approach was chosen as it was considered the best way to capture the researchers' evolving understanding of the students' and tutors' experience of the course through the data collected throughout the semester. This first phase of analysis involved identifying recurring initial themes under 'Student feedback', 'Tutor feedback' and 'Tutorial observation'. Similarities were then identified between these initial themes and final themes were established. The 
research questions and the identification of themes were driven by the data and constantly revised and refined.

The first two authors led the initial analysis of the data. Initial themes (in light of all findings) were later discussed and finalised in collaboration with the third and fourth authors, who also provided feedback on the final discussion.

\section{Study findings and discussion}

Findings are presented under four main themes: 'Reality check: the impact of the general teaching and learning environment'; 'Low initial expectations and polarised satisfaction'; 'Intercultural communication at work'; and 'Disposition towards engagement, critical thinking, and reflexivity'.

\section{Reality check: the impact of the general teaching and learning environment}

The impact of the general teaching and learning environment is seldom addressed in the literature, yet it amounts to real challenges teachers and students have to face. Physical and 'digital' disruptions, fluctuating attendance, level of preparedness and engagement, and level of English proficiency were the key factors found in the data as impacting on teaching and learning.

Physical, 'digital' disruptions and fluctuating attendance. Class attendance is not compulsory at RMIT University with a sizable impact on the quality of tutorials for all students. It is particularly noticeable in a course on Intercultural Communication which requires robust class discussion aiming to nurture critical thinking and reflexivity over the length of a whole semester. Many students hold part-time or full-time work and find it difficult to attend all their classes. Decreased attendance, as the semester progresses and students have more assignments to submit, was also noted. Coupled with work commitments, assessment submission deadlines affect class attendance.

Class observation showed that in most tutorials, some students arrive late and leave early without prior notice. Others leave the classroom to go to the toilet or take a phone call and use their mobile phones and laptops for purposes unrelated to the course (e.g., browsing the internet, answering emails). These disruptions are a recurring topic of discussion at the weekly tutors' meeting. Tutors who respond to digital disruptions and prohibit the non-course related use of devices tend to have more engaged students in the classroom. This is despite having to deal with some students who resist being asked to not make use of devices for non-course related purposes. 
The 'fluctuating' tutorial attendance was not only mentioned by tutors, but also students: 'I found the fluctuating attendance to be disruptive to the constructive and effective running of the tutorial; [this] coupled with a non-essential attendance policy renders the whole idea of tutorials obsolete'.

Preparedness and engagement. The lack of preparedness for tutorials was mentioned by both tutors and learners for different reasons but all linked to the quality of class engagement.

Class observation showed that most (but not all) tutors owned the course content, showed evidence of having prepared for their tutorial (having listened to the lecture and done the reading) and brought their own academic knowledge and personal experiences to class discussions. Those factors contributed greatly to their ability to successfully engage students. Tutors who appeared bored and unengaged with the course content and tutorial activities (as noted by some students), tended to be those who conducted their classes in a more teacher-centered fashion, and were consequently less successful at engaging their class. In one tutorial, a very engaged student was clearly dissatisfied with the tutor's inability to engage more critically with the tutorial activity and to answer questions on the reading for the week to their satisfaction.

Students' comments on their tutors were divided. The ability to motivate students, being helpful, stimulating, and passionate about the course, as well as creating a safe class environment for discussion were seen as important qualities:

$\mathrm{X}$ was a fabulous teacher. His passion for the subject and course content was contagious and made me want to work harder'; 'This course also held really intriguing discussions, and $\mathrm{X}$ always created a safe space for us to share our thoughts and opinions without judgement.

Conversely, negative comments from students included a perceived lack of knowledge from tutors, not being engaged themselves with the course content and not knowing how to engage students:

The tutor doesn't seem to have an in-depth knowledge of the texts'; 'My tutor didn't know how to make other people talk'; 'My tutor often seemed kind of bored and this meant the people in my class were not particularly motivated to attend classes and contribute to discussion'; ' $\mathrm{X}$ could interact with the class more rather than sitting behind his desk for the whole workshop. 
New tutors reported they had a lot to learn themselves in order to be ready for their tutorials as a lot of the course contained content new to them. Most felt the course covered too much too quickly, that it could easily be split over two semesters, and that students needed more time to engage with new concepts.

Group dynamics varied enormously and did not appear to be linked solely to tutors' ability to engage the class, but rather to student profiles and individual dispositions towards the course. For example, some tutorials offered in the evening attracted more mature-age students who attended more regularly and welcomed robust critical debate, in turn attributable to their higher level of maturity.

The above findings show the importance of tutor and student preparedness in order to engage with the course content, albeit critically. They also show the importance of training tutors on how to engage a class, since most tutors in the course have no training in pedagogy. Tutors' weekly meetings aim to provide pedagogical support, albeit in a limited way due to time constraints.

Level of academic English proficiency matters. All tutors reported on the majority of students needing more support in firstly simply reading, secondly in reading critically, and thirdly in writing in academic English. They also noted that Generation Z students (so-called 'digital natives'), the majority in the course, appear to partially read online materials rather than pages of reading from a book or articles. Getting students to read a weekly reading of 20 to 30 pages is therefore the first challenge. The first assessable task for the course is 'Reading logs', which aim to provide an incentive for students to read the weekly readings and to train them to reflect on them critically, including taking notes to that effect. Students in the study reported mixed feelings on the reading logs, finding them too time consuming and/or finding that, because the logs forced them to do the readings, they led to increased satisfaction with the course content and tutorial discussions, as they increased their capacity to engage critically.

Tutors commented specifically on students whose first language is not English, namely international students, or domestic students who arrive in Australia with low English proficiency, meaning that they were unable to read academic texts as easily as a native speaker might reasonably be expected to, nor were they able to engage in tutorials critically. Some students (native speakers of English) reported on the hindrance of having students in their tutorial who could not engage in discussion at a level they expected in an academic environment due to their low level of English proficiency.

Knowing how to mark assignments written in poor English was also mentioned as a challenge for tutors. One international student from China contacted the course coordinator asking for different criteria in marking their work. The issue of English proficiency is highly political and seldom overtly recognised for the 
impact it has on teaching and learning practices. Support for reading and writing in academic English is built into tutorial activities but only to an extent. Tutors regularly refer students who need extra support to academic English support services.

All the above findings clearly illustrate the many challenges that need to be addressed on an on-going basis as part of the general learning environment and running of the course. The next challenge the teaching team face is students' low initial expectations from the course.

\section{Low initial expectations and polarised satisfaction}

Students' wording of their expectations at the start of the course speaks to the general lack of recognition, in public discourse, of intercultural communication as an academic subject of value in its own right. Unlike knowledge of world languages (e.g., Chinese, Arabic) which can be perceived as added value giving access to a global elite (Barakos \& Selleck, 2019), knowledge of intercultural communication, on its own, is usually not perceived as such. One of the first challenges tutors face when starting the course is students' negative attitudes towards it.

Although the majority of students appeared to not really know what to expect, others said they expected little from it or were surprised by its content: ' $I$ had really low expectations'; 'I thought the course appeared very basic'; 'I expected it to be a bland topic - I was completely surprised'.

Several students commented on their lived experience of interculturality, which contributed to their initial devaluing of the course, until they appreciated its academic value, as illustrated in the following student's comment:

I had really low expectations... I come from a very intercultural background so it was frustrating to have to do this course, it's compulsory. I have a personal interest in this topic but I've never studied it in an academic setting but this course got me to look at it from an academic perspective and really get that historical, scholarly background to a lot of the topics. Really great to be given all this wealth of knowledge and great articles to go back to and be able to refer to and take my understanding to the next level.

Levels of satisfaction with the course were very polarised. They could not be related statistically to students' areas of study as responses are anonymous, and only some students made that connection explicit in their feedback. However, students from the same discipline sometimes provided opposite responses, for example: 'I very much viewed it as a kind of toolbox course. I am doing social work and that's about human interaction and about talking to people', versus 'How this is a core subject for social work is beyond me'. 
The most recurring positive adjective was 'interesting' ('very/extremely interesting'). Other positive comments included 'stimulating', 'eye opening and very useful for everyday life,, 'extremely fascinating and relevant to my studies', 'mind-blowing course, makes you question not only the world but yourself.' Such positive comments often accompanied high levels of satisfaction with the course content and structure, the type of assessments, and readings. These findings suggest that despite initial low expectations, for some students at least, the course delivered positive learnings.

Negative comments tended to be linked to a perceived lack of connection with a student's area of study, dissatisfaction with the assignments, amount and content of reading, as well as new terminology: 'This is the most useless content for my course, there is no correlation, shouldn't be a core subject for international studies course, and too many assignments'; 'very very dry content, not interesting at all, very complex terminology'.

Many students appreciated the practical outcomes ('a very practical course where I could apply the theories in a more practical way, that I could actually use in my day-to-day life'), while others felt there were none ('it would have been interesting if the content was practical and applied to real life scenarios').

It is difficult to fully interpret students' polarised views without being able to correlate them with the actual versus the intended content delivered in the lectures and tutorials. Nonetheless, class observation and also ethnographic notes from the tutors' weekly meetings suggest that at least the tutors' interpretation of the course content and their approach to tutorial activities impact greatly on the kind of learnings students take home. Students' positive predisposition to critical thinking, self-introspection, and to dealing with complexity, as well as simply to diligent study, also impact on the quality of learning. In the above students' comments, 'useless content' is also associated with 'too many assignments' and 'very dry content' to 'very complex terminology'.

\section{Intercultural Communication at work}

The reference to tangible knowledge that can be learnt and applied in a work context echoes other students' comments above describing the course as a 'toolbox' and as 'useful' and 'practical', learning to potentially challenge essentialist perceptions of culture:

Often the content from this course was in mind when I was at work and communicating with people from different cultures and in a way this new understanding helped me feel more comfortable when speaking with different people; ultimately it provided very useful knowledge for any future careers as well as everyday communication settings. 
Some felt that the course overgeneralised cultural traits. Others wanted more concrete culture-specific examples, while others deplored what they perceived as a lack of accounting for variability and individual agency in intercultural communication:

Most of the facts and knowledge obtained are general'; 'The content can be very dry e.g.: The French speak this way, English speak this way, too much generalisations, doesn't take the individual into account;

Personally, I found the content very strict and not accurate because it is all about justifying why cultures do what they do which is not taking the individual into account. For example, having a visual impairment means I am ALWAYS being grabbed, pushed, pulled, and snatched by members of the public. They believe they are being helpful but in what culture is physically touching someone okay?

One exchange student mentioned what they perceived to be an Australian pedagogy which they were not accustomed to: 'Sometimes the course content is not easy for international students to understand. The information is presented in an Aussie way rather than a universal way'. It is difficult to know what this student means by 'Aussie way' versus a 'universal way' of teaching but it points to the need to take better account of students' different educational backgrounds and address these overtly as potential spaces of discomfort to explore.

It is clear from the above findings that despite the course intent to: a) not essentialise cultures and take account of variability as well as individual agency; and b) to focus on interculturality as primarily criticality and reflexivity, extra care and time (as suggested by tutors) are needed, at least for some students, in approaching the necessarily very nuanced and complex content that a course on intercultural communication calls for.

Disposition towards engagement, critical thinking, and reflexivity

Tutors described the course as challenging, promoting intellectual growth and introspection, complex, rigorous, stimulating, and with a clear narrative running throughout. One tutor referred to it as 'a hard in a good way course'. All also agreed that the more subjective aspect of the course (self-reflection) was the most difficult for students, but also the most rewarding. They noted that the course requires a level of maturity beyond some students who found the course too confronting, some resisting criticality and introspection, 'being too rigid in their thinking', expecting the course to focus only on the 'other' and not themselves. Some tutors reported that a student occasionally left a tutorial in anger or disagreement, which points to 
the highly sensitive and challenging practice of learning and teaching intercultural communication, and the fact that it is a fluid dynamic process which changes over time. Tutors also noted that halfway through the course, 'things come together', 'the penny drops', and students start to engage more critically in class discussions.

Group dynamics varied enormously and did not appear to be linked solely to the tutors' ability to engage the class, but also to student profiles and individual dispositions towards the course. As well as the mature-age students who welcomed critical debate, students appeared most engaged when relating their own personal experiences and sharing light-bulb moments during tutorial activities. For example, in the week on identity, in one tutorial a student shared that after listening to the lecture, doing the reading, and watching the video for that week she had finally been able to start feeling more comfortable with being 'Chinese-Australian'. Another referred to the course as having supported her to own her dual identity a bit better:

Another thing that I really like is that I feel a lot more comfortable in myself. At the start of this course when $\mathrm{X}$ asked my class what do you identify as, I said a white-washed Indian and now I think I have a lot more ownership of my identity. I can be two things. I don't necessarily have to pick and choose. It feels like before I was taught about all this it felt like I had to pick and select.

Some students valued being given the opportunity for deeper, reflective, more 'personal' learning which they noted impacted positively on their own development: '... the content makes you change what you think, even though you don't realise that's how you think. It's really good, a personal kind of learning'; 'mind-blowing course, makes you question not only the world but yourself'.

A very small number of students voiced their discontent with what they perceived as racism towards Anglo-Australians and othering and/or overvictimisation of other groups: 'Don't make all whites evil and Aboriginals misunderstood'; 'This course often presents as anti-Australia, anti-white, and antiChristian'; 'In class, people from other cultures were often singled out to provide their experiences, creating a sense of "othering"'. These comments align with tutors' pointing to careful consideration always needed in the way the course content is approached and, regardless, of the challenges in dealing with the array of responses it can trigger in students.

Catering for all possible students' responses to the course in advance is not possible. The tutors' meetings, however, provided a space for debriefing what occurred during tutorials, and discussing future strategies to support students, as well as the teaching team (course coordinator and tutors), in always developing 
further the capacity for practising interculturality as part of attending as well as teaching a course on Intercultural Communication.

\section{Conclusions}

Findings from the study provide rich insights into a range of issues covered by our research question: What and who-in other words which aspects of society, identity and self are at stake when teaching and learning about language and interculturality from a critical perspective?. We propose speculations rather than conclusions, as we are well aware of the limitations of the project and the need for further research.

What our study shows is that there is a lot at stake in teaching and learning in an intercultural communication course which is critically oriented. Core issues are to do with the commonly disruptive learning and teaching environment, students' initial low expectations towards the course, what ought to constitute knowledge for intercultural communication, and the ability and willingness to engage in criticality for all involved (course coordinator, tutors, and students).

Our findings show that there is no ideal learning and teaching environment where all students and tutors are 100 percent committed to the course. Many disruptions and inadequate levels of preparedness are outside the course coordinator's immediate control but need to be taken into account in terms of what can be realistically expected from the course delivery. Overcoming students' initial low expectations from the course is another challenge the teaching team has to address. The notion that there is something to learn about how language and the fluidity of culture work together in shaping not only others' worldview, but also one's own worldview, is new to most students, who are usually not consciously aware that they live in language and culture. As tutors noticed, 'the penny drops' for many students halfway through the course. One way of supporting more students to see their selves among others as Holliday (2018) suggested, would be to build more consistent activities tied to the different weekly topics with that specific aim. This also supports the finding from tutorial observation that students appeared most engaged when they shared intercultural personal experiences they can relate to the course.

Students' expectations of practical learning outcomes can be associated with their implicit understanding of culture as factual knowledge that can be learnt and later applied. However, we cannot assume that all students hold essentialist views of culture. Firstly, some students complained about what they perceived to be cultural overgeneralisations in the course. Others, perhaps more accurately, understood that although the course does make statements about different cultures, 
it also considers variability and individual agency in the critical interpretation of all human interaction. It is important to understand that when Holliday (2018) warns against teaching essentialist blocks in Intercultural Communication courses, it does not imply that no cultural categorisation is ever possible. Acknowledging that different and knowable cultural categories (e.g., Western, Eastern, Indigenous) do exist ensures that power struggles between them are not ignored (Manathunga, 2015), a point which is highly relevant in a course which takes a critical perspective on intercultural communication.

Juxtaposing students' perceptions of tutors' performance with tutors' comments on challenges, engaging students critically was shown to depend greatly on tutors' disposition towards the course, including pedagogical aptitudes. Understanding students' learning is also crucial to successful teaching in critical Intercultural Communication courses. Although our data do not allow us to extrapolate on students' backgrounds, it is clear that they all come to the course with very different social, cultural, and linguistic capital. This is most obvious in the comments made by international students who struggle with English proficiency and the Australian educative culture. It is also relevant to tutors' comments that most students (despite their background) need more support in reading and writing in academic English.

Students, tutors, and the coordinator all bring their diverse capital, histories, personal sensitivities to the course. What our study clearly shows is that a critical approach to teaching the course calls for a conscious practice of critical intercultural communication between teaching staff and between teaching staff and students, in itself requiring high political and ethical engagement. It involves recognising that a critical Intercultural Communication course is what Bourdieu (1991) would call 'the space of relations' imbibed with symbolic power play. What does this awareness imply in terms of improving the course?

If the aim of a critical Intercultural Communication course is to transform mirrors into windows (Huber-Kriegler, Lázár, \& Strange, 2003), that is, to move students from introspection to an openness to other possible forms of selves in order to function better among different others, further understanding of the different factors involved in this process is crucial. Our study represents a first step in this direction.

There are several limitations in our study which further research will need to address. More research is needed on students' backgrounds, their educative, linguistic, social, and cultural capital, not only to better assess the impact on their ability to engage in the course but to assist in re-imagining the course from a transcultural pedagogical perspective (Song \& Cadman, 2012). This would include reconsidering the course content and pedagogy from non-Western perspectives and 
seeking to engage students and the teaching team in non-Western systems of knowledge and of learning, including Indigenous-Australian systems.

When designing the course, the coordinator was inspired by the literature on critical language and intercultural communication education. Future research could consider assessing the course's intent versus its actual content and delivery (i.e., lectures and tutorials). This would include reviewing the course assessment, an area not explicitly considered here, yet one which greatly concerns students. Future research could also examine the ongoing professional development required for tutors, aiming to make it not such 'a hard in a good way course' to teach.

\section{Acknowledgements}

We wish to thank the tutors and students who contributed to the research project that inspired this article. 


\section{Author biographies}

Chantal Crozet is a teacher-researcher in the School of Global, Urban and Social Studies at RMIT University in Melbourne. She teaches French language \& culture, and intercultural communication. Her research interests include Language \& Intercultural Education, non-Western systems of thoughts on knowing, Multi-lingual/cultural identities and selves, French language and gender.

Kerry Mullan is Convenor of Languages at RMIT University in Melbourne, where she teaches French language and culture, and linguistics. Her main research interests are cross-cultural pragmatics and intercultural communication, discourse analysis, language pedagogy, and verbal humour in social and online interactions (particularly French and Australian).

Jing $Q i$ is an educational researcher in the School of Global, Urban and Social Studies, RMIT. Jing draws together experience in multilingual, sociological, cultural and technological studies to bring an innovative perspective to educational research. Her research focuses on the politics of knowledge in intercultural education (particularly knowledge contributions from the Global South). She also publishes in teacher education and international education.

Masoud Kianpour received a $\mathrm{PhD}$ in sociology from the Memorial University of Newfoundland (Canada) in 2010 and has been an Assistant Professor of sociology at the University of Isfahan in Iran since September 2011. As of 2017, Masoud has been an associate member at RMIT's Social and Global Studies Center in Melbourne, Australia, where he has participated in various research activities. His areas of research and teaching include social psychology, sociology of emotions, mental health, intercultural communication, social problems and medical sociology. 


\section{References}

Abdallah-Pretceille, M. (2006). Interculturalism as a paradigm for thinking about diversity. Intercultural Education, 17(5), 475-483. https://doi.org/10.1080/14675980601065764

Alia, V. (2014). The new media nation: Indigenous peoples and global communication. New York: Berghahn Books.

Alim, H. S., Rickford, J. R., \& Ball, A. F. (2016). Raciolinguistics: How language shapes our ideas about race. Oxford: Oxford University Press.

Barakos, E., \& Selleck, C. (2019). Elite multilingualism: Discourses, practices, and debates. Journal of Multilingual and Multicultural Development, 40(5), 361-374. https://doi.org/10.1080/01434632.2018.1543691

Bauman, Z. (2004). Identity: Conversations with Benedetto Vecchi. Cambridge, UK: Polity Press.

Bourdieu, P. (1991). Language and symbolic power. Cambridge, MA: Harvard University Press.

Bowen, A. (2019). 'You don't have to say anything': Modality and consequences in conversations about the right to silence in the Northern Territory. Australian Journal of Linguistics, 39(3), 347-374.

Braun, V., \& Clarke, V. (2006). Using thematic analysis in psychology. Qualitative Research in Psychology, 3(2), 77-101.

Crozet, C. (1996). Teaching verbal interaction and culture in the language classroom. Australian Review of Applied Linguistics 19(2), 37-58.

Crozet, C. (2016). On language and interculturality: Teaching languages and cultures for a global world. In J. C. H. Lee (Ed.), Narratives of globalisation - Reflections on the global condition (pp. 85-94). London: Rowan \& Littlefield.

Crozet, C. (2018). Engagement politique et approche interculturelle, diffusion du français en milieu tertiaire non-francophone. In I. Pierozak, M. Debono, V. Feussi, \& E. Huver (Eds.), Penser les diversités linguistiques et culturelles. Francophonies, formations à distance, migrances (pp. 203-216). Limoges, France: Lambert Lucas.

Crozet, C., \& Diaz, A. R. (2020). Tertiary language-teacher researchers between ethics and politics: Silent voices, unseized spaces. London: Routledge.

Dasli, M., \& Diaz, A. R. (Eds.) (2017). The critical turn in language and intercultural pedagogy: Theory, research and practice. London: Routledge.

Dervin, F. (2016). Interculturality in education. London: Palgrave Macmillan.

Dervin, F., \& Liddicoat, A. J. (2016). Linguistics for intercultural education. Amsterdam: John Benjamins. 
Diaz, A. R. (2013). Developing critical languaculture pedagogies in higher education: Theory and practice. Bristol: Multilingual Matters.

Diaz, A. R., \& Moore, P. J. (2019). (Re)imagining a course in intercultural communication for the $21^{\text {st }}$ century. Intercultural Communication Education, 1(3), 84-99.

Eades, D. (2004). Understanding Aboriginal English in the legal system: A critical sociolinguistics approach. Applied Linguistics, 25(4), 491-512.

Eades, D. (2008). Telling and retelling your story in court: Questions, assumptions and intercultural implications. Current Issues in Criminal Justice 20(2), 209-230.

Eisenchlas, S. A., \& Trevaskes, S. (2003). Teaching intercultural communication in the university setting: An Australian perspective. Intercultural Education, 14(4), 397-408.

Gibbons, J. (2003). Forensic linguistics: An introduction to language in the justice system. Malden, MA: Blackwell.

Gudykunst, W. B., Ting-Toomey, S., \& Wiseman, R. L. (1991). Taming the beast: Designing a course in intercultural communication. Communication Education, 40(3), 272-285.

Hatoss, A. (2019). Linguistic landscapes - An experiential learning project for developing intercultural competence. Australian Review of Applied Linguistics, 42(2), 146-170.

Hattersley, C. (2014). Birr Nganka Nyikina: The Source of Nyikina Language. Broome, Australia: Madjulla Inc.

Heiss, A. (Ed.) (2018). Growing up Aboriginal in Australia. Melbourne: Schwartz. Holliday, A. (2018). Designing a course in intercultural education. Intercultural Communication Education, 1(1), 4-11.

Hua, Z., Handford, M., \& Young, T. (2017). Framing interculturality: A corpusbased analysis of on-line promotional discourse of higher education intercultural communication courses. Journal of Multilingual and Multicultural Development, 38(3), 283-300.

Huber-Kriegler, M., Lázár, I., \& Strange, J. (2003). Mirrors and windows - An intercultural communication textbook. Strasbourg: Council of Europe.

Kendall, S., \& Tannen, D. (2001). Discourse and gender. In D. Schiffrin, D. Tanner, \& H. E. Hamilton (Eds.), The handbook of discourse analysis (pp. 548567). Malden, MA: Blackwell.

Kohler, M. (2015). Teachers as mediators in the foreign language classroom. Bristol: Multilingual Matters.

Lee, A., Poch, R., Shaw, M., \& Williams, R. D. (2012). Engaging diversity in undergraduate classrooms: A pedagogy for developing intercultural competence. ASHE Higher Education Report. San Francisco: Jossey-Bass. 
Liddicoat, A. J., \& Crozet, C. (2001). The acquisition of French pragmatic norms through formal instruction. In K. Rose \& G. Kasper (Eds.), Pragmatics in language teaching (pp. 125-144). New York: Cambridge University Press.

Liddicoat, A. J., \& Scarino, A. (2013). Intercultural language teaching and learning. Malden, MA: Wiley-Blackwell.

Lo Bianco, J., \& Crozet, C. (Eds.) (2003). Teaching invisible culture, classroom practice and theory. Melbourne: Language Australia.

Lo Bianco, J., Liddicoat, A. J., \& Crozet, C. (Eds.) (1999). Striving for the third place - Intercultural competence through language education. Melbourne: Language Australia.

Manathunga, C. (2015). Transcultural and postcolonial explorations: Unsettling education. The International Education Journal: Comparative Perspectives, 14(2), 10-21.

Martin, J. N., Nakayama, T. K., \& Carbaugh, D. (2014). The history and development of the study of intercultural communication and applied linguistics. In J. Jackson (Ed.), The Routledge handbook of language and intercultural communication (pp. 17-36). London: Routledge.

Mikander, P., Zilliacus, H., \& Holm, G. F. (2018). Intercultural education in transition: Nordic perspectives. Education Inquiry, 9(1), 40-56.

Moore, T. (2016). Interculturality, postethnicity and the Aboriginal Australian policy future. Ethnicities, 16(5), 712-732.

Mullan, K. (2015). Taking French interactional style into the classroom. System, $48,35-47$.

Mullan, K. (2017). Et pis bon, ben alors voilà quoi! Teaching those pesky discourse markers. International Journal of the Pedagogies of Learning (special issue: 'Pedagogies and diverse classrooms') 11(3), 271-282.

Roby, W. B. (1992). Intercultural communication education and foreign language education: Shared precedents, procedures, and prospects. Intercultural Communication Studies, 2(1), 43-56.

Simpson, A., \& Dervin, F. (2019). The Council of Europe Reference Framework of Competences for Democratic Culture: Ideological refractions, othering and obedient politics. Intercultural Communication Education, 2(3), 102-119.

Song, X., \& Cadman, K. (2012). Bridging transcultural divides: Asian languages and cultures in global higher education. Adelaide: University of Adelaide Press.

Verschueren, J. (2008). Intercultural communication and the challenges of migration. Language and Intercultural Communication, 8(1), 21-35.

Yi-jung Hsieh, T. (2019). Theoretical and practical considerations in the design of an intercultural communication course. Australian Review of Applied Linguistics, 42(2), 171-191. 